\title{
THE METABOLISM OF THE ISOLATED HEART OF DOGS RELATED TO AGE ${ }^{1}$
}

\author{
By A. E. COHN ANd J. M. STEELE \\ (From the Hospital of the Rockefeller Institute for Medical Research, New York)
}

(Received for publication July 15, 1935)

In attempting to understand disability of a chronic nature, more particularly in that group of ailments commonly designated as "degenerative diseases," it has become ever more apparent that description of the successive phases which healthy individuals exhibit during normal life is extraordinarily incomplete. A serious defect in knowledge accordingly exists which interferes in an important sense with the possibility of drawing conclusions concerning how far a particular healthy person differs from his fellows. In short the question as to whether his bodily state differs only so widely from the average as to fall within the range of chance biologic variation, or so widely as to lie outside and by so doing suggest the influence of some unknown agent must, for the most part, go unanswered.

A living organism is obviously the expression of the sum of the functions of its organs and structures, and these in turn depend for their behavior upon the units of which they are composed. It is well established (1), furthermore, that the growth and decay of the body and its parts follow curves of different rates of change when plotted against age. The thymus gland, for instance, reaches the peak of its development at puberty while the posterior molar teeth are not usually fully developed until the age of thirty. It follows, seemingly, that only by accumulating descriptions of change of the parts with age can change of the whole become known or understood.

The study of growth in human beings, especially of their organs and tissues, is beset with many difficulties. Their relative longevity, the complexity involved in unravelling the rôle of their inherited characteristics and the uncontrollability of environmental factors lead to variations so great as to tend to obscure the essential phenomena relevant to a description of ontogenetic

1 This paper is also No. 16 of the Series on Physiological Ontogeny published from the Hospital of the Rockefeller Institute. progress. In order to attempt an understanding of such processes the observer is forced to turn to the study of animals. The advantages of choosing, as has been done in this study, such an animal as pure-bred wire-haired fox terriers are apparent. They have a homogeneous ancestry, have a suitable size, and their ages can be known. Female specimens only were chosen. They may, furthermore, be furnished with similar food, exposed to the same climatic conditions and allowed to partake of similar physical activity. A certain simplification in the problem of managing the effect of environmental factors on aging is, in this way, achieved. Under these circumstances a variety of studies of dogs of this breed have been undertaken. The present communication deals with the relation of the metabolism of the heart, as indicated by the consumption of oxygen and elimination of carbon dioxide, to the age of the animal.

\section{METHODS}

The method by which the heart and lungs were isolated from the rest of the body was essentially that of Knowlton and Starling (2). The operative technique need not be described except to mention the use of a knife in circuit with a high frequency current for cutting the soft tissue overlying the sternum. The time consumed in operating was, by this means, reduced materially. The amount of blood lost was negligible. The total capacity of the external circulation was $700 \mathrm{cc}$. The blood was warmed, and its temperature satisfactorily controlled during the time of its passage through a thinwalled rubber reservoir when the latter was immersed in water heated by an electric bulb thermostatically regulated. The level of the warm water around the reservoir was maintained uniform automatically (3) so that the venous pressure was constant.

The apparatus for analyzing respiratory gases differs in some particulars from most of those reported and is, therefore, described in greater detail. Starling's “Ideal respiration pump" was used for inflating the lungs. By means of three-way stopcocks one in the inspiratory and one in the expiratory tube, the respiratory system could be connected with the "closed" spirometer circuit (Figure 1). The air in the spirometer circuit was propelled at a rate of five liters a minute by a rotary pump through 


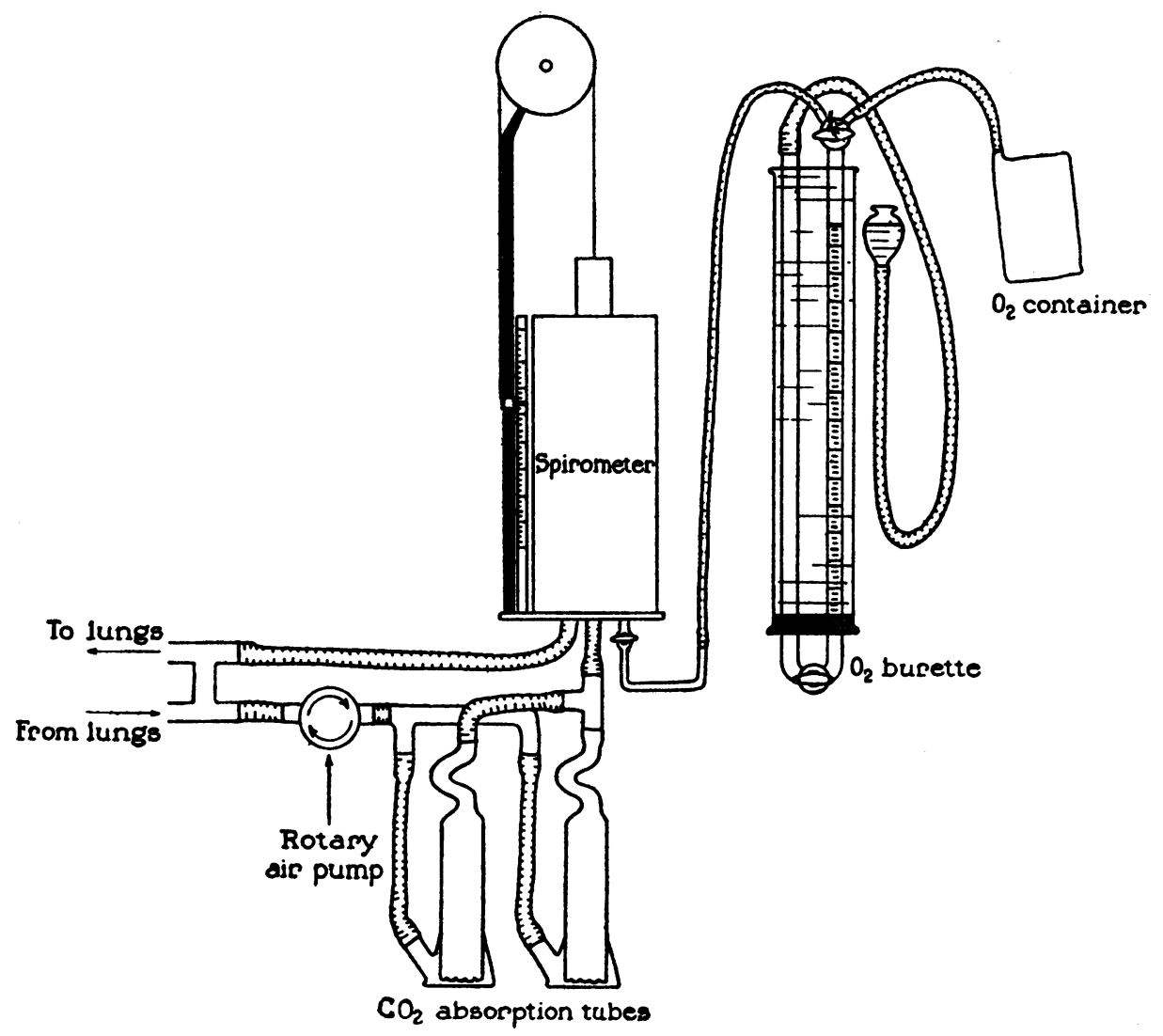

Fig. 1. A Diagram of the Apparatus Used for Analyzing and Keeping Uniform the Mixture OF RESPIRATORY GASES

See description in text.

one of a pair of receptacles each containing sodium hydroxide (20 per cent solution) to absorb carbon dioxide. The air then passed on into a spirometer and from there to the respiratory pump. The rate of movement chosen insured the passage onward of the expiratory air away from the inspiratory inlet before that valve opened.

The carbon dioxide excreted was absorbed in a known volume of sodium hydroxide solution, and the amount given off within a measured period of time (within 8 to 10 minutes) was calculated from the concentration of gas in the solution (4). The amount of oxygen consumed was calculated not from the fall of the spirometer, but from the amount it was necessary to add in order to keep it at the same level. This method was adopted because to maintain gaseous equilibrium between the blood perfusing the preparation and the respiratory air, it was essential that the preparation be supplied with air of constant composition. The quantity of oxygen added within a given time was measured in a calibrated burette of $100 \mathrm{cc}$. capacity from which it was displaced by water pressure into the closed respiratory system. The rate of passage was controlled by a screw clamp. By means of an indicator the original level of the spirometer could be reproduced approximately within one-quarter of a millimeter, or $0.7 \mathrm{cc}$. Since the smallest volume of oxygen measured was $30 \mathrm{cc}$. the error involved in this manoeuver was less than 2.4 per cent. The burette was easily read with an accuracy of $0.1 \mathrm{cc}$. so that the error from this source was not more than 0.3 per cent.

Changes in temperature introduced a small additional error. The volume of the respiratory circuit was one liter, and the rate of movement of air such that practically uniform temperature prevailed throughout the system. The greatest change encountered during any one measurement was $0.2^{\circ} \mathrm{C}$. Complete neglect of change in temperature of the air in the lungs (roughly $200 \mathrm{cc}$.) would contribute an error of only $0.2 \mathrm{cc}$. and since the temperature of the circuit was ascertained to within $0.05^{\circ} \mathrm{C}$. the error from this source was also $0.2 \mathrm{cc}$. The maximal error in correction of volume for changes of temperature was, accordingly, 1.2 per cent. The actual error was perhaps less than one-half this amount. All these errors combined constitute, at a maximum, a theoretical error of 4 per cent. It was found that duplicate measurements did not often differ by more than 3.5 
per cent and that the average difference between duplicates was 2.5 per 'cent.

The animals were kept without food for 18 hours prior to operation. Anesthesia was induced by injecting chloralose 0.1 gram per kilo body weight, into any convenient vein anesthetized locally with novocaine. Other sedative drugs were not given. Not infrequently it was necessary to supplement the original dose of chloralose by as much as 0.05 gram per kilo. Rarely the dose was doubled. One fatality was obviously due to chloralose in over a hundred animals. Eighty-five consecutive experiments were carried out without the appearance of pulmonary edema except as an event associated with heart failure near the close of an experiment. In the eightysixth animal, however, this accident developed abruptly ten minutes after changing to the external or artificial circulation. This was the third successive experiment in which a small amount of ether by inhalation had been given as a substitute for an additional dose of chloralose. The practice was immediately discontinued, and in the remaining twenty-eight experiments pulmonary edema did not occur. Additional blood was obtained from a mongrel by bleeding from the carotid artery five minutes after heparin (10 grams per kilo) had been injected intravenously. The bleeding was carried out without anesthesia unless the animal became restless; ether was then administered.

After the circulation had been diverted to the artificial circulating system, a cannula connected to a water manometer was inserted into the right auricle through the inferior vena cava. The rubber tube from the arterial cannula was connected by a side arm to a mercury manometer. Plungers riding the liquid in the manometers wrote on a smoked drum.

The cardiac output was measured in a stromuhr brought into the circuit by turning a large glass cock, through which there were three passages-one, inlet and outlet, to each side of the stromuhr, and a by-pass. The borings are necessarily so arranged that on turning the cock from its central, by-pass, position, passage is provided for simultaneous flow into one side and evacuation of the other side of the instrument. ${ }^{2}$ The output of the heart and the arterial pressure were adjusted to the desired levels.

Enough of a 10 per cent solution of glucose containing one unit of insulin (Lilly and Co.) for each gram of glucose was rapidly added to raise its concentration in the blood to between 200 and $250 \mathrm{mgm}$. per $100 \mathrm{cc}$. This usually required about a gram of glucose; the amount in the blood was estimated by the micro-time method of Hawkins (5). The glucose-insulin mixture was added mechanically at a uniform rate of 8 to $15 \mathrm{cc}$. an hour, depending upon the size of the heart. Often the rate chosen served to keep the concentration of glucose constant, but somewhat more frequently it rose slowly to a level of 300 to $350 \mathrm{mgm}$. glucose per $100 \mathrm{cc}$. of blood. The rate of injection was not changed, how-

2 A description of the stromuhr and the stopcock will be published elsewhere. ever, since it was observed that a reduction, or a sudden increase, in the inflow of the glucose-insulin mixture led to prompt changes in the efficiency of the heart.

About twenty minutes after changing to the artificial circulation, the respiratory system was connected to the spirometer circuit by turning the two 3-way cocks. Ten minutes were allowed to pass to permit the expiratory volume of the lungs to become adjusted to the slight difference in pressure existing between the respiratory and spirometer systems. Measurements of the consumption of oxygen and of the elimination of carbon dioxide were then begun in immediately successive periods of eight to twelve minutes. Constant values were obtained, usually within forty minutes, always within an hour. Unless signs of heart failure made their appearance, a fairly unchanging period in the life of the preparation was now established. Constancy of behavior was manifested in the uniformity of the cardiac output, of the venous and arterial pressures, as well as in the rate of metabolism. This was almost invariably the period of greatest efficiency lasting usually about an hour and not infrequently, two hours. Only those experiments in which a plateau of behavior like this persisted for at least a half-hour were included in the study which is now reported.

Several other tests of the constancy or well-being of the preparation were carried out from time to time (Table I). (I) Great changes in hydrogen ion con-

TABLE I

The results of analyses of samples of the blood perfusing the heart and lungs at the beginning and end of the period of observation in a number of experiments. The shortest interval between any pair of measurements was fifty minutes, the longest two hours and five minutes

\begin{tabular}{|c|c|c|c|c|c|c|c|c|}
\hline \multirow{2}{*}{$\begin{array}{c}\text { Dog } \\
\text { num. } \\
\text { ber }\end{array}$} & \multicolumn{4}{|c|}{$\begin{array}{l}\text { At the beginning of the } \\
\text { experiment }\end{array}$} & \multicolumn{4}{|c|}{$\begin{array}{l}\text { At the end of the } \\
\text { experiment }\end{array}$} \\
\hline & $\mathrm{O}_{2}$ & $\mathrm{CO}_{2}$ & $\mathrm{pH}$ & $\begin{array}{c}\text { Lactic } \\
\text { acid }\end{array}$ & $\mathrm{O}_{2}$ & $\mathrm{CO}_{2}$ & $\mathrm{pH}$ & \begin{tabular}{|c} 
Lactic \\
acid
\end{tabular} \\
\hline & $\begin{array}{c}\text { ool- } \\
\text { umes } \\
\text { per cent }\end{array}$ & $\begin{array}{c}\text { vol- } \\
\text { umes } \\
\text { per cen }\end{array}$ & & $\begin{array}{c}\mathrm{mgm} . \\
\text { per } \\
100 \mathrm{cc} .\end{array}$ & $\begin{array}{c}\text { vol- } \\
\text { umes } \\
\text { per cent }\end{array}$ & $\begin{array}{c}\text { vol- } \\
\text { umes } \\
\text { per cen }\end{array}$ & & $\begin{array}{c}\text { mgm. } \\
\text { per } \\
100 \text { cc. }\end{array}$ \\
\hline $\begin{array}{l}119 \\
120\end{array}$ & $\begin{array}{l}11.24 \\
12.34\end{array}$ & $\begin{array}{l}8.84 \\
8.36\end{array}$ & & & $\begin{array}{l}12.45 \\
12.25\end{array}$ & 8.69 & & \\
\hline $\begin{array}{l}120 \\
138\end{array}$ & $\begin{array}{l}12.04 \\
16.50\end{array}$ & $\begin{array}{l}0 . \\
7 .\end{array}$ & & & 15.80 & $\begin{array}{l}8.10 \\
8.10\end{array}$ & & \\
\hline 147 & & 9. & & & & 11.02 & & \\
\hline & 14.0 & 8.4 & & & 13.38 & 9.02 & & \\
\hline 164 & 18 & 7. & & & & & & \\
\hline 165 & & 6.3 & & & & 7.07 & & \\
\hline $\begin{array}{l}182 \\
203\end{array}$ & $\begin{array}{l}15.91 \\
15.70\end{array}$ & 7.23 & 7.68 & & 15.12 & 7.84 & 7.62 & \begin{tabular}{|l|}
51.2 \\
\end{tabular} \\
\hline 204 & & & & 42.50 & & & & \\
\hline $\begin{array}{l}207 \\
208\end{array}$ & & & $\mid \begin{array}{l}7.64 \\
7.72\end{array}$ & \begin{tabular}{|l|}
50.30 \\
40.70
\end{tabular} & & & & 44 \\
\hline 209 & 16.27 & 9.24 & 7.64 & 38.75 & 15.40 & 8.60 & 7.67 & 41.6 \\
\hline
\end{tabular}

centration, as measured by the colorimetric method of Hastings and Sendroy (6) were not encountered. The high degree of alkalinity is, of course, due in part to the fact that only the heart and lungs instead of the whole 
body were producing carbon dioxide, and in part to the large volume of the ventilation employed, but so large a volume was necessary in order to maintain the lungs in good condition and the blood sufficiently oxygenated. The effect of this set of artificial conditions is also reflected in the low content of carbon dioxide in the blood. During the period when measurement of metabolism was going on, there was but little change in concentration of either carbon dioxide or oxygen (Table I). (II) The presence and multiplication of bacteria in the perfusing blood was also investigated. The chief sources of infection lay in the rubber dam constituting the artificial resistance and in the rubber of the venous reservoir. But if these were kept, between experiments, in alcohol 70 per cent it was necessary to do no more to sterilize the apparatus than to wash the glassware and the rest of the rubber tubing with soap and water, to allow it to dry, and then, when the parts were assembled, to flush the whole with a few hundred cubic centimeters of fresh Ringer's solution just before the experiment. With the use of this procedure it was usually impossible to cultivate bacteria on blood agar plates. Occasionally at the end of 3 hours, three or four colonies per cubic centimeter were found, on one occasion eighteen. (III) The concentration of lactic acid in the blood was measured (7) from time to time at the beginning and end of the periods of observation. The largest increase was $6 \mathrm{mgm}$. in each $100 \mathrm{cc}$. of blood. (IV) Oxygen and carbon dioxide content of the blood were also measured (4) at the beginning and end of a number of experiments. Significant changes were not observed.

The heart was weighed within 15 minutes of the termination of the experiment. After injection with a barium sulphate mixture $\mathbf{x}$-ray photographs were made to study the arterial blood supply. This investigation will form the body of a separate communication. The fat around the base of the heart as well as the aorta and the pulmonary artery were next removed. Their weight was subtracted from the total weight of the heart. The consumption of oxygen ${ }^{3}$ was calculated according to the wet weight per gram of auricle and ventricle.

Only those experiments in which the following criteria were fulfilled were considered suitable for analysis:

1. The preparation must have attained and held for at least half-an-hour a steady state in regard to cardiac output, arterial and venous pressures, and rate of consumption of oxygen.

2. The respiratory quotient must have remained within reasonable limits; greater than 0.80 and less than 1.05 .

3. At least two pairs of estimations of the consumption of oxygen must have been obtained differing from each other by less than 7 per cent (the estimated error of measurement of oxygen was 3.5 per cent) so that

3 Throughout the remainder of the paper consumption of oxygen is employed instead of the more exact phrase - consumption of oxygen per gram of heart per hour.

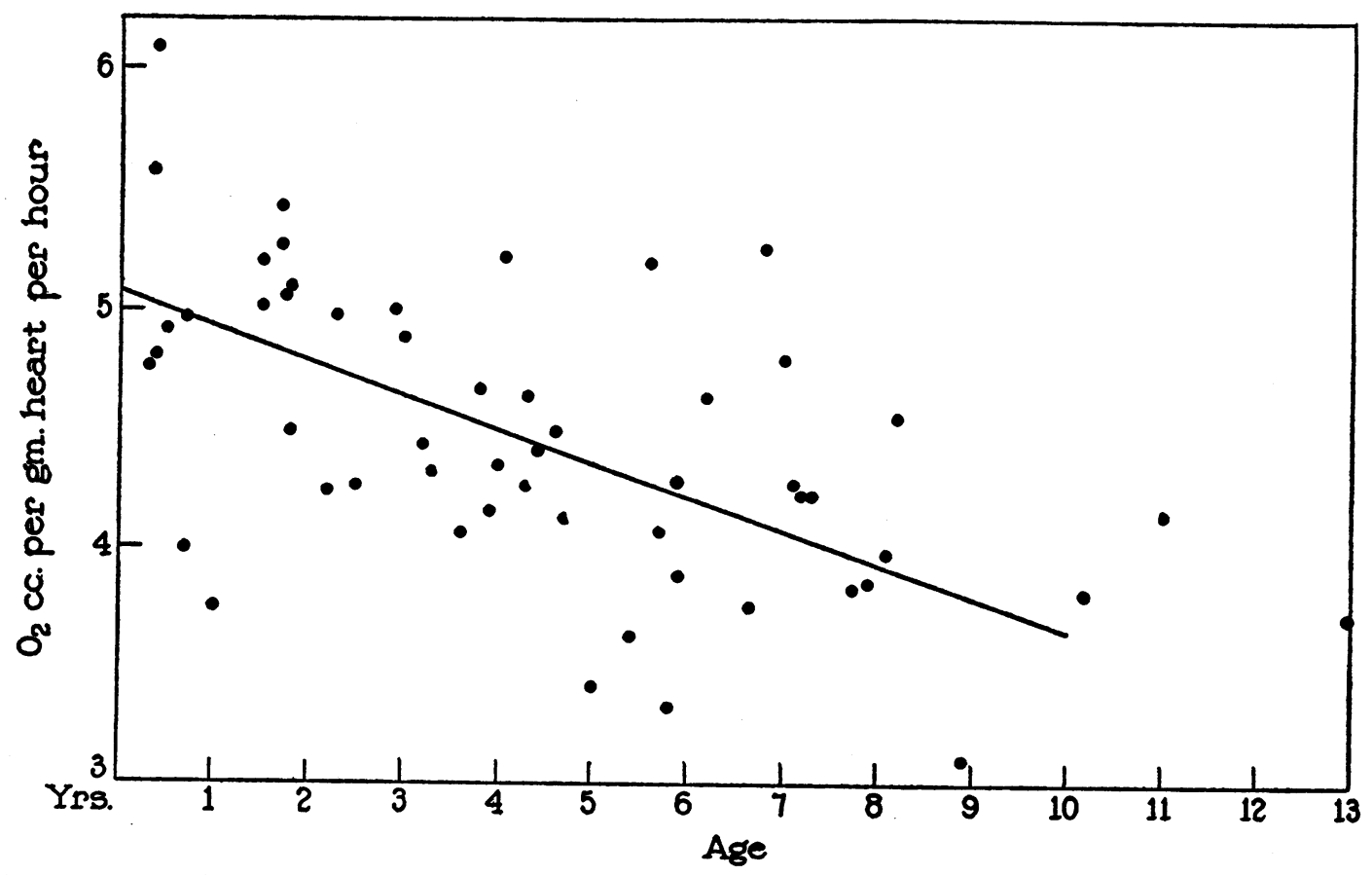

FIG. 2.

The values for the consumption of oxygen by the heart are plotted against the age of the animal and the regression line is drawn. 


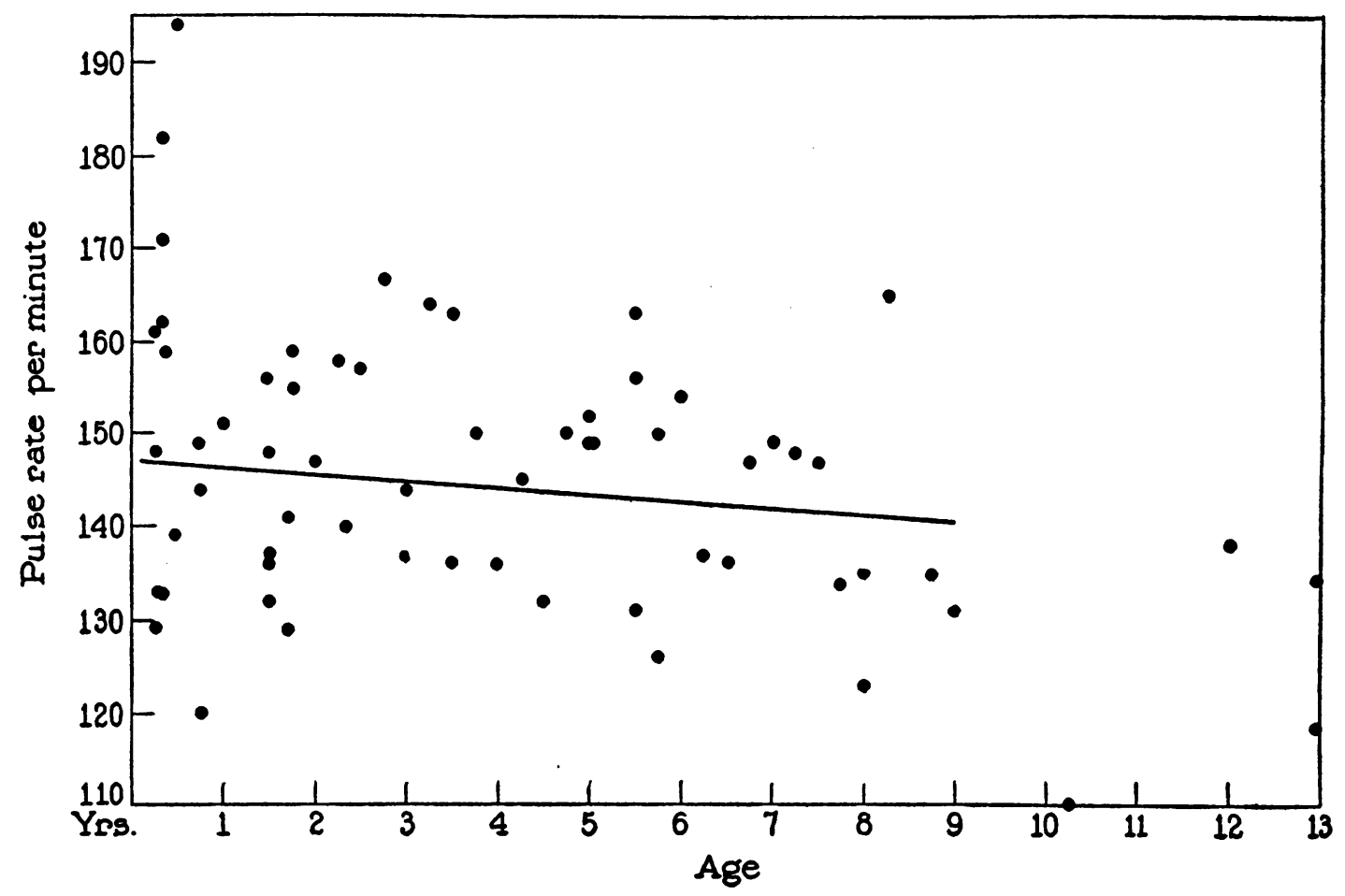

FIG. 3.

Observations on the rate of contraction assumed naturally by each heart are plotted in relation to the age of the animal and the regression line drawn.

there might be assurance that the system was in equilibrium.

There are, of course, in heart-lung preparations countless variable factors beside the two (age of the animal and consumption of oxygen by the heart) which were the subject of this study. Many are known and can either be regulated or their effect calculated, but many more are unknown. To the unknown ones is due the unaccountable variability of metabolism from one animal to the next. It is obviously advantageous that variation in the two factors under investigation be as great, and in all others as small, as possible. Attempt was made with reasonable success to eliminate variation in such factors as temperature, diastolic length of muscle fiber, cardiac output, venous and arterial pressure and composition of the blood in respect to concentration of oxygen, carbon dioxide, sugar, lactic acid and hydrogen ions. The frequency of the heart beat naturally varied. To regulate it was found to be impracticable. The size of the heart also varied due to the different ages of the animals. The influence of certain of these factors has been studied; their effect is described later.

\section{RESULTS}

The results are summarized briefly:

1. The consumption of oxygen per gram of heart decreases with age (Figure 2). The crude coefficient of correlation was -0.6002 .

2. The frequency of the heart beat decreases with age (Figure 3 ).

3. The consumption of oxygen per gram of heart increases with rate (Figure 4 ). The coefficient of correlation was +0.4706 . The suggestion emerges accordingly that part of the decrease in the consumption of oxygen with age may be due to the decrease in the frequency of contraction. What influence frequency of contraction exerts on consumption of oxygen at successive ages can be calculated, were all the hearts assumed to beat at the same rate. The relation (frequency of contraction and consumption of oxygen) is shown in the curve (Figure 4) and is expressed by the formula :

Consumption of oxygen per gram of heart per hour $=0.187$ number of contractions per minute $+2.23(8)$.

The influence of this relation with respect to age can now be taken into account by modifying the 


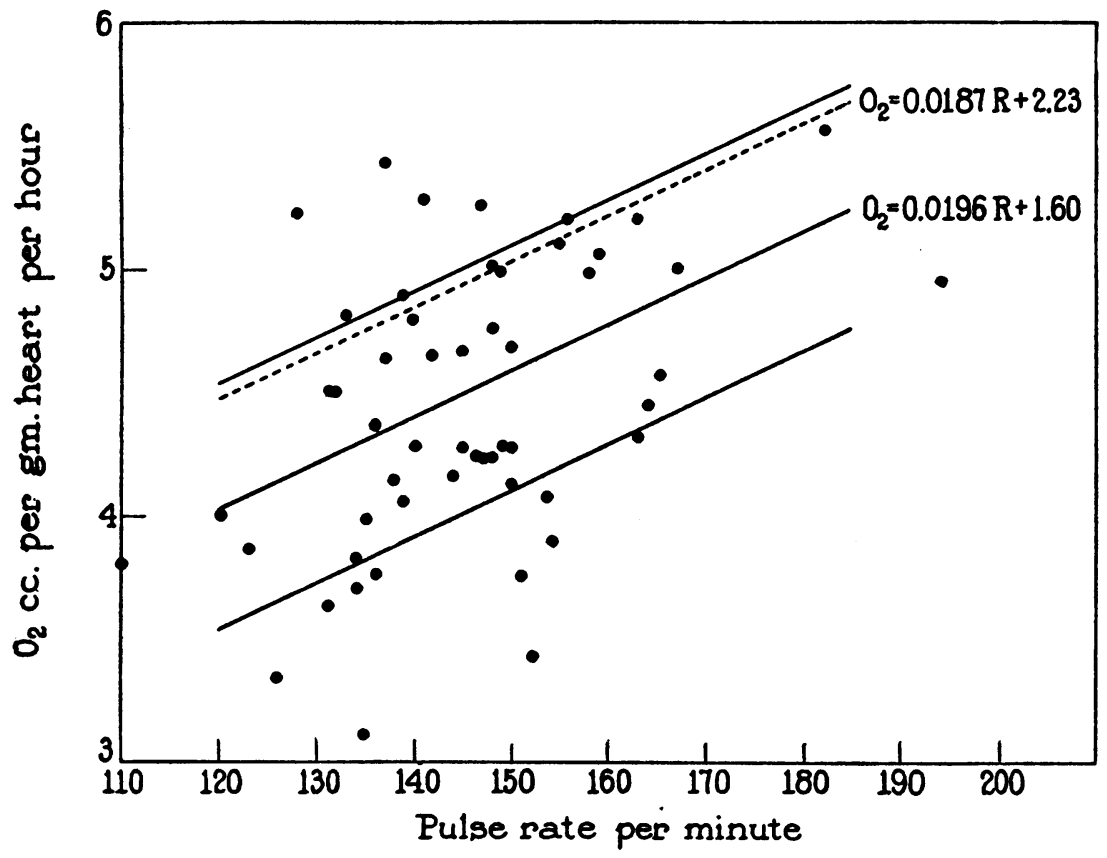

Fig. 4.

The rate of consumption of oxygen of each heart is plotted according to the frequency of contraction. The regression line is drawn in. The dotted line represents the equation expressing the relation between frequency of contraction and consumption of oxygen obtained in a different manner (8).

original results (Figure 2). The method of partial correlation (9) permits this calculation. The resulting coefficient of correlation is found to be -0.5016 . This figure, though less than the original one $(-0.6002)$ is still significant in that the probability of the occurrence of this relation by chance is only one in a thousand.

4. The size of the heart is related both to age and to the amount of oxygen consumed. Larger hearts use less oxygen per unit of weight than smaller ones (Figure 5), the coefficient of correlation being - 0.5421 . Since adult hearts are larger than younger ones (Figure 6) a coefficient of correlation of +0.5852 of age with size results. It is obvious that as the heart increases in size with age (Figure 6 ), and since the rate of consumption of oxygen per unit of weight decreases with increase in the weight of the heart (Figure 5), the apparent decrease in consumption of oxygen with age may, in part, be due to increase in size of the heart. Size of the heart and frequency of its beat both accordingly affect the consumption of oxygen per unit of weight apart

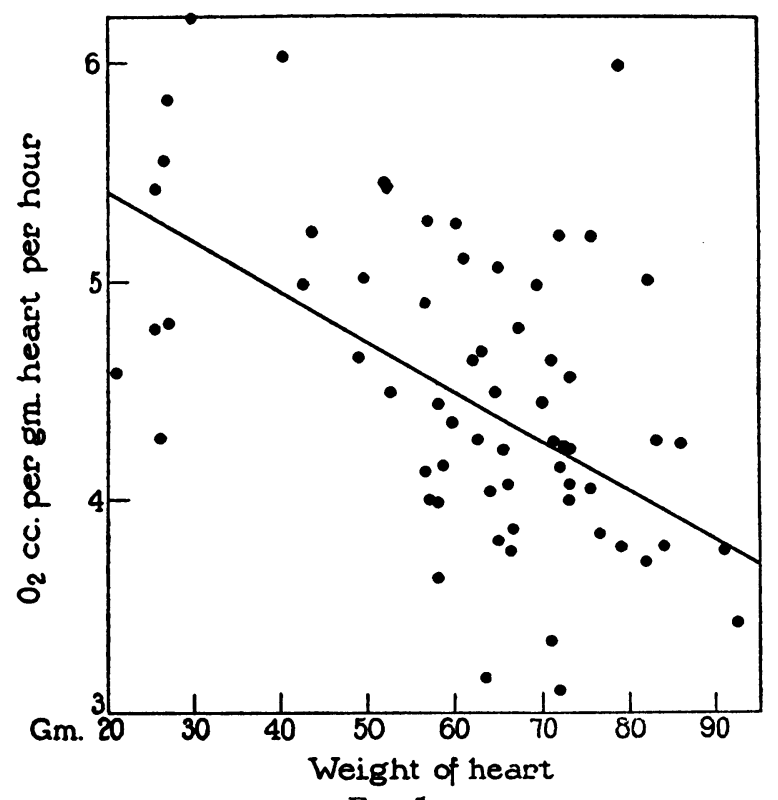

FIG. 5.

This diagram expresses the relation found between size of heart and consumption of oxygen per unit of weight. Dots indicate the individual observations; the line, the regression equation. 


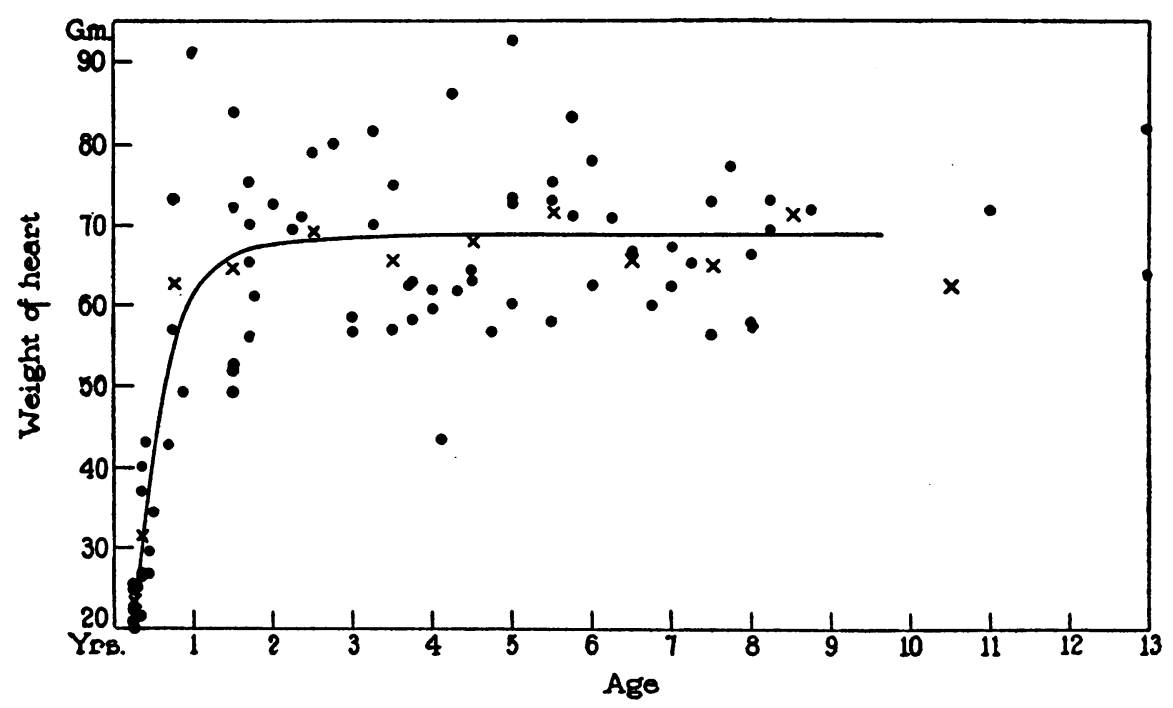

FIG. 6.

Weights of hearts are charted as dots according to age. The curve was drawn in in the manner of Brody (Growth and development. III. Growth rates, their evaluation and significance. Missouri Agric. Exper. Station. Research Bull. 97, January 1927).

from the effect of age. The effect of age alone therefore (on the consumption of oxygen) dwindles; the partial correlation coefficient expressive of this fact (the relation between age and consumption of oxygen) falls to -0.3561 . This figure is of doubtful significance, for the probability of its expressing an accidental relationship is greater than one in twenty.

But the curve of increase in size of heart with age is clearly not linear but logarithmic (Figure $6)$. After $1 \frac{1}{2}$ years of age, little if any change in size of the heart occurs and exerts, consequently, little influence on the relation between oxygen and age. The coefficient of correlation between weight and age, for dogs above one year old, drops to an insignificant figure $(+0.2172)$, while that between weight and consumption of oxygen increases $(-0.5904)$. If the process of calculating the partial correlation coefficient of age and oxygen, independent of the influences of weight of heart and frequency of contraction is repeated for the groups above one year of age, the coefficient is somewhat enhanced, rather than reduced, as it was in the whole group, by making allowances for the two additional variables. The coefficient is now -0.6040 which is, according to Fisher (10), a highly significant figure.
If corrections are made for the functions of size and frequency of contraction, a significant degree of correlation between age and consumption of oxygen remains. Without these corrections a high degree of correlation exists and is expressive of the integrated behavior of the heart as a whole according to age, for those changes in frequency and size which have been discounted are themselves likely to be intrinsically connected with changes in function with time both in the heart and in the whole animal.

5. The amount of work to be performed by the hearts could be regulated, as is customary in these preparations, by arranging venous and arterial pressures. They were, in fact, so arranged that the correlation between age and work turned out to be insignificant, the coefficient being +0.0918 . In this manner work, although directly related to consumption of oxygen, was shown to exert no greater influence on one age group than on another.

6. When all the variables of which one can take account are considered, and their influence upon the consumption of oxygen is weighed in their relation to age, it appears that consumption of oxygen by the heart decreases as that organ grows older. A considerable and unaccountable 
variation still exists which, expressed in terms of the standard error of estimate, amounts to $\pm 0.5 \mathrm{cc}$. of oxygen per gram of heart. Its occurrence may be taken as a simple and clear statement of the fact that additional variable quantities are operative of which no knowledge exists.

These results suggest that decrease in frequency of beat and increase in size of the heart with age do not account altogether for the decrease with age which has been found in the rate of consumption of oxygen by that organ. Although in the intact animal all of these factors are operative, perhaps even to a greater degree than in the heartlung preparation, there occurs in addition some change expressive of a more fundamental one in the heart with age. Whether the change involves substitution of muscle by some less active tissue, fat for example, or some intrinsic change or changes in composition of the muscle fibers, is a question which remains unanswered. Evidence that changes of both sorts occur, exists, but to find it has naturally not formed part of this investigation.

\section{CONCLUSION}

Decrease in the consumption of oxygen with age was observed in heart-lung preparations made in pure-bred female wire-haired fox terriers of known age living under similar environmental conditions and having been given similar food. Those variable factors in the life of the preparation which could be arranged were controlled; the effects of those which were uncontrollable were calculated. The degree of relationship between age and consumption of oxygen per unit of weight of heart was considerably less when account was taken of certain functions found to be related to both (age and oxygen consumption) but was still significant.

The evidence suggests that, although rate of contraction, size, and, in intact animals, the amount of work done, play a part in the decrease of metabolism with age, there is in addition a change in structure of the heart or in its composition with age which leads to reduction in the amount of oxygen consumed by each unit of its weight.

A technical observation is believed to be of sufficient importance to deserve mention in the conclusion. When the lungs are exposed to ether even for brief periods, they are likely to become edematous-but apparently not otherwise.

\section{BIBLIOGRAPHY}

1. Cohn, A. E., and Murray, H. A., Jr., Physiological ontogeny. I. The present status of the problem. Quart. Rev. Biol., 1927, 2, 469.

2. Knowlton, F. P., and Starling, E. H., The influence of variations in temperature and blood pressure on the performance of the isolated mammalian heart. J. Physiol., 1912, 44, 206.

3. Bayliss, L. E., Müller, E. A., and Starling, E. H., The action of insulin and sugar on the respiratory quotient and metabolism of the heart-lung preparation. J. Physiol., 1928, 65, 33.

4. Van Slyke, D. D., and Neill, J. M., The determination of gases in blood and other solutions by vacuum extraction and manometric measurement. J. Biol. Chem., 1924, 61, 523.

5. Hawkins, J. A., A micro-time method for determination of reducing sugars and its application to analysis of blood and urine. J. Biol. Chem., 1929, 84, 69.

6. Hastings, A. B., and Sendroy, J., Jr., Studies of acidosis. XX. The colorimetric determination of blood $\mathrm{pH}$ at body temperature without buffer standards. J. Biol. Chem., 1924, 61, 695.

7. Avery, B. F., and Hastings, A. B., A gasometric method for the determination of lactic acid in the blood. J. Biol. Chem., 1931-32, 94, 273.

8. Cohn, A. E., and Steele, J. M., Am. J. Physiol. (In press.)

9. Wallace, H. A., and Snedecor, G. W., Correlation and machine calculation. Iowa State College of Agriculture and Mechanic Arts. Official publication. 1931, Vol. 30, No. 4.

10. Fisher, R. A., Statistical methods for research workers. Oliver and Boyd, London, 1930, 3rd ed. 